\title{
Research on the factors affecting the successful implementation of Lean production model in industrial production enterprises in Vietnam
}

\author{
Hoàng Thị Hương \\ Department of Business Management \\ Hanoi university of Industry \\ Hanoi, VietNam \\ Hoangthihuong@.haui.edu.vn \\ TEL.0983938467
}

\author{
Nguyễn Thị Mai Anh \\ Department of Business Management \\ Hanoi university of Industry \\ Hanoi, VietNam \\ Nguyenthimaianh@haui.edu.vn
}

\begin{abstract}
Lean manufacturing is one of the modern management methods to streamline production, reduce waste and increase business efficiency, thereby helping organizations and businesses improve productivity and quality. Most businesses have encountered difficulties when converting to LEAN and have not achieved the expected and sustained results in the long term. The aim of his study is to evaluate the factors of business characteristics affecting the results of Lean model application in industrial production in Vietnam. This study conducts an indepth study of 10 typical industrial manufacturing enterprises. The research results show a model of six business characteristics that affect the success of Lean in production conditions in industrial enterprises. Based on the results, this study provides some suggestions for the firms to successfully apply lean.
\end{abstract}

Index Terms-Lean, success, characteristics, industrial production enterprises

\section{INTRODUCTION}

$\mathrm{T}$ HE LEAN production method is built on the foundation of continuous improvement with the aim of eliminating waste in the production process and helping businesses build a unified thinking and action method for the production process. $[5 ; 16]$. The concept of LEAN has been studied in many fields, expressed in two well-known and in-depth studies of Womack \& Jones, "The Machine that Changed the World" in 1990 and the research work "LEAN Thinking" which is evaluated by experts was simultaneously published in 2003. The basis of LEAN production is the Toyota Production System (TPS) with a new concept of production based on innovation and building consensus among people to create new higher value from and within the business. From the successful experience and strong development of Toyota $[1 ; 21 ; 25]$ up to now, the LEAN philosophy has become a new trend in high-efficiency and zero-waste manufacturing. $[6 ; 8 ; 15 ; 18]$ In fact, there are many businesses in the world that have been participating in the transition to LEAN production for a long time, but most of the results achieved are only modest costs compared with expectations $[4 ; 7 ; 10 ; 11]$.

In Vietnam, the lean production model has been awakened in both research and practice. There are many studies on LEAN that have been published by many researchers. Along with some initial results, there are also many businesses that have not achieved success in the process of applying the LEAN production method to the production system. Most businesses have encountered difficulties when converting to LEAN and have not achieved the expected and sustained re- sults in the long term. In fact, there are not many enterprises that apply and succeed with the LEAN production method in Vietnam $[13 ; 14 ; 15]$. Only about less than $10 \%$ of these enterprises have the ability to successfully approach this production method. [13;20]. From some of the above issues, the author focuses on in-depth research at 10 industrial production enterprises that have applied LEAN to the production system to find out what are the factors affecting the successful application of LEAN in Vietnam. Vietnam [16;18;19;22]. The study focuses on identifying and evaluating the factors affecting the successful application of LEAN and the characteristics of enterprises that affect the results of applying LEAN in enterprises to explain why many businesses in Vietnam have difficulties in successfully applying LEAN.

\section{Literature Review and Research Model}

The term "success factors" is defined as "a limited number of factors that, when satisfied, will ensure the performance and enhance the competitive success of the enterprise." Success factors are identified as the most important factors affecting the success of an organization when implementing a new program or project $[18 ; 19 ; 24]$. Success factor research will help businesses know and focus on a few areas that may meet these criteria or may even allow businesses to decide if they have the necessary capabilities $[1 ; 10]$.

Clearly defining the criteria to successful application of LEAN in the production system helps the author to accurately analyze the process and evaluate the implementation results of the enterprises. Previous studies have shown that the results of LEAN are expressed through four main criteria: (1) increase production productivity, (2) improve product quality, (3) reduce production costs and (4) ability to deliver on time $[9 ; 12 ; 17]$. These criteria are considered to be the most important to determine the successful application of LEAN in enterprises [30;31]. An enterprise is considered to have successfully applied LEAN when that enterprise has applied LEAN for at least 3 years and the results must meet all 4 criteria. Moreover, these results have been maintained for at least 1 year [26]. There are two levels of enterprise success in adopting LEAN which depend on when the implementation started or be applied and the results from the adoption process. Accordingly, the levels include: (1) Applying LEAN internally inside the firm and (2) Extending LEAN beyond the firm. 


\section{A. Factors for the successful application of Lean model}

Based on the literature review, in order to investigate the factors affecting successful implication of Lean, the author focuses on 10 industrial production enterprises with more than 5 years applying Lean. Currently, there is no detailed study on the factors affecting the successful application of the Lean model in industrial production enterprises. Previous research results show that six problems of industrial production enterprises affect the successful application of the Lean model, including: (1) Leadership commitment to companionship, (2) Technology level, (3) Management competences, (4) Quality of employees, (5) The awareness of the workforce about the importance of Lean and (6) Supply chain integration ability. Based on the literature review, we propose the research model as follow:

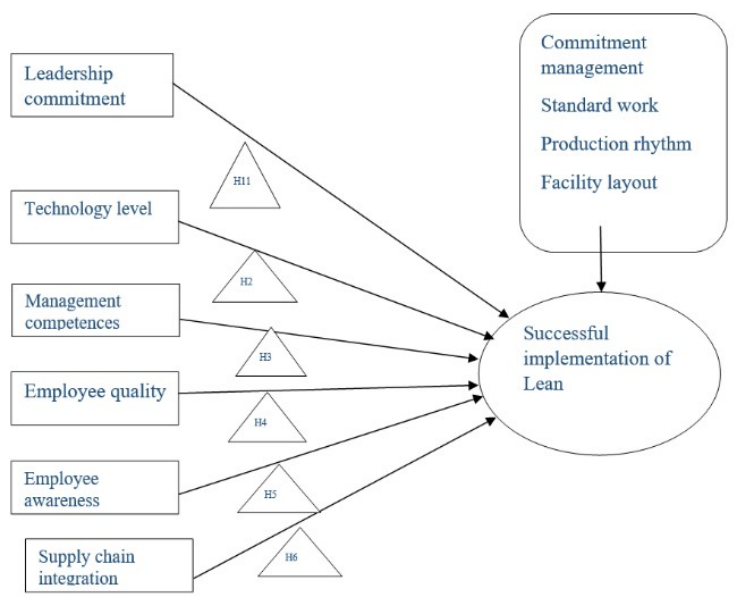

Figure 1. Research model

The following research hypotheses are proposed:

Hypothesis H1: Leadership commitment has a positive impact on Successful implementation of Lean

Hypothesis H2: Technology level has a positive effect on Successful implementation of Lean

Hypothesis H3: Management competence has a positive impact on Successful implementation of Lean

Hypothesis H4: Employee quality has a positive impact on Successful implementation of Lean

Hypothesis H5: Employee awareness has a positive impact on Successful implementation of Lean

Hypothesis H6: Supply chain integration has a positive impact on Successful implementation of Lean

\section{Research Methods}

The study used qualitative research methods combined with quantitative research. Qualitative research aims to: determine the factors affecting the ability to successfully apply the Lean model, determine the research model, adjust the scales of research concepts on the basis of building a draft scale that is summarized Conclusions from previous studies were referenced to form a preliminary interview questionnaire. The survey was conducted through the technique of consulting 5 experts ( 5 managers knowledgeable about the technical process of quality control). Research, in-depth interviews with 90 workers working at production spans, on production lines in factories arranged with Lean applications, warehouses, etc. We choose a convenient sampling method to check preliminary questionnaires, adjust the scales to suit the reality of each operation in the production stages, because each production process requires a level of standardization of the stages and very strict operation (cycle time) by rationalizing the production processes. Quantitative research helps to quantify the relationship between factors through the application of statistical analysis tools (SPSS), using 5-level Likert scale to measure the values of observed variables.[3,6, 22, $23,24,25 ; 30]$

The study sample size was determined on the principle of being larger than the minimum sample size to achieve the necessary reliability of the study. According to, the minimum sample size must be guaranteed according to the formula $\mathrm{n} \geq$ $8 m+50$, the author's research model includes 06 independent variables, so the minimum sample size is $=8 * 6+50=$ 98 observations; In the study, the author chose a sample size of 150 to ensure reliability for data analysis. Collecting primary data from a structured questionnaire prepared through stratified probability sampling method. Survey subjects were selected from many lines in the workshop at companies producing different product lines. Various products include: fixed line, variable line, continuous production line, assembly and packaging management system, raw material storage, finished product storage, automatic welding workshop. The data analysis was conducted in the following steps: first, we assessed the reliability of the scale by Cronbach's Alpha coefficient, then we conducted exploratory factor analysis (EFA). Finally, to test the hypotheses we did correlation analysis and multiple linear regression $[3,6]$.

\section{Research Results}

\section{A. The reliability of the scale}

The results of data analysis showed that the scales were reliable (Cronbach's Alpha $>0.6$ ). Thus, the scale is suitable for exploratory factor analysis (EFA).

Table 1. Evaluation of SCale Reliability

\begin{tabular}{|l|c|l|l|l|}
\hline The scale & $\begin{array}{l}\text { The } \\
\text { number } \\
\text { of } \\
\text { observed } \\
\text { variables }\end{array}$ & $\begin{array}{l}\text { Coefficient of } \\
\text { correlation of } \\
\text { total variables. }\end{array}$ & $\begin{array}{l}\text { Cronba } \\
\text { ch' } \\
\text { Alpha } \\
\text { coeffi- } \\
\text { cient. }\end{array}$ & $\begin{array}{l}\text { Cronbach' } \\
\text { Alpha if } \\
\text { variable type }\end{array}$ \\
\hline $\begin{array}{l}\text { Leadership } \\
\text { commitment (LD) }\end{array}$ & 4 & $0.711-0.829$ & 0.917 & $0.893-0.911$ \\
\hline $\begin{array}{l}\text { Technology level } \\
\text { (CN) }\end{array}$ & 4 & $0.623-0.693$ & 0.849 & $0.808-0.828$ \\
\hline $\begin{array}{l}\text { Management } \\
\text { competences(NL }\end{array}$ & 5 & $0.598-0.680$ & 0.809 & $0.734-0.775$ \\
\hline Labor quality (LQ) & 4 & $0.677-0.800$ & 0.879 & $0.820-0.868$ \\
\hline $\begin{array}{l}\text { Employee } \\
\text { awareness (NT) }\end{array}$ & 5 & $0.627-0.794$ & 0.845 & $0.755-0.825$ \\
\hline $\begin{array}{l}\text { Supply Chain } \\
\text { integration (CC) }\end{array}$ & 4 & $0.555-0.642$ & 0.780 & $0.699-0.742$ \\
\hline
\end{tabular}


EFA exploratory factor analysis: After the variables have been evaluated, and the scales of the variables are suitable. The KMO coefficient is between 0.5 and 1 and the model's significance coefficient according to Bartlett's test must be statistically significant at 5\%. The variables with Factor loading less than 0.5 in EFA would be omitted from the research model.

\begin{tabular}{|c|c|c|c|c|c|c|}
\hline \multirow{2}{*}{ Variable } & \multirow[b]{2}{*}{1} & \multicolumn{5}{|c|}{ Load factor } \\
\hline & & 2 & 3 & 4 & 5 & 6 \\
\hline LD6 & 0.887 & & & & & \\
\hline LD5 & 0.875 & & & & & \\
\hline LD1 & 0.850 & & & & & \\
\hline LD4 & 0.817 & & & & & \\
\hline LD2 & 0.815 & & & & & \\
\hline NL3 & & 0.777 & & & & \\
\hline NL5 & & 0.682 & & & & \\
\hline NL4 & & 0.618 & & & & \\
\hline NL2 & & 0.572 & & & & \\
\hline NL1 & & & 0.821 & & & \\
\hline LQ2 & & & 0.819 & & & \\
\hline LQ4 & & & 0.786 & & & \\
\hline LQ3 & & & 0.763 & & & \\
\hline LQ1 & & & 0.752 & & & \\
\hline NT3 & & & & 0.894 & & \\
\hline NT2 & & & & 0.860 & & \\
\hline NT4 & & & & 0.850 & & \\
\hline NT1 & & & & 0.814 & & \\
\hline $\mathrm{CC} 2$ & & & & & 0.896 & \\
\hline $\mathrm{CC} 1$ & & & & & 0.831 & \\
\hline $\mathrm{CC} 4$ & & & & & 0.786 & \\
\hline $\mathrm{CC} 3$ & & & & & 0.784 & \\
\hline $\mathrm{CN} 2$ & & & & & & 0.835 \\
\hline $\mathrm{CN} 3$ & & & & & & 0.797 \\
\hline CN1 & & & & & & 0.781 \\
\hline $\mathrm{CN} 4$ & & & & & & 0.773 \\
\hline DISCLAIM & $\mathrm{ER} 8,54$ & 219,613 & 32,34 & 45,244 & 57,245 & 68,461 \\
\hline Eigenvalues & 4,537 & 3,327 & 3,127 & 3,026 & 2,58 & 2,477 \\
\hline
\end{tabular}

- Factor analysis with scales of independent variables

EFA analysis for independent variables: The results of 06 factors analysis with 26 observed variables showed that: $\mathrm{KMO}$ value $=0.824(0.5<\mathrm{KMO}=0.824<1)$, so factor analysis is accepted with data research material; Sig coefficient. $=0.000<0.005 ;$ Cumulative variance of 06 extracted factors $=68.461 \%>50 \%$. The variation of 06 factors represents $68.461 \%$ of the overall variation. This is a high percentage indicating that the data obtained from the survey has a high degree of convergence of the scale.

EFA analysis for the dependent variable: the results of factor analysis with 04 observed variables showed that: KMO value $=0.752(0.5<\mathrm{KMO}=0.752<1)$ satisfied the suitability of factor analysis; Sig coefficient. $=0.000<0.005$; Cumulative variance extracted $=60.412 \%>50 \%$; All factors meet the conditions with Eigenvalue $=2,416>1$ to form a statistically significant factor $[4 ; 14]$. Thus, the factor analysis has given completely reliable results, these factors will be saved directly into the data of SPSS software with specific names as stated in the summary table. These factors will be used in regression analysis to evaluate the influence of each factor on the success of Lean.

After EFA verification and automatic saving of factors in the analysis process, independent factors are given including Leadership commitment to accompany, technology level, management capacity, quality labor, awareness of the workforce, and the ability to link supply chains are six factors that have a positive impact on the success when applying the Lean model to production and business activities of enterprises.

Table 2. Results of Regression Analysis

\begin{tabular}{|l|l|l|l|l|}
\hline Model & $\mathrm{R}$ & $\mathrm{R}^{2}$ & $\begin{array}{l}\text { Standard } \\
\text { deviation }\end{array}$ & $\begin{array}{l}\text { Durbin- } \\
\text { Watson }\end{array}$ \\
\hline 1 & $0.799 \mathrm{a}$ & 0.639 & 0.337 & 1.783 \\
\hline & $\begin{array}{l}\text { Sum of } \\
\text { squares }\end{array}$ & $\begin{array}{l}\text { Degree } \\
\text { of } \\
\text { Freedom }\end{array}$ & $\mathrm{F}$ & Sig \\
\hline Regression & 56,644 & 6 & 99,808 & $0,000 \mathrm{~b}$ \\
\hline Balance & 32,009 & 144 & & \\
\hline Total & 88,563 & 150 & & \\
\hline
\end{tabular}

(Source: the author's survey data processing results.)

Multiple linear regression analysis was performed using the Enter method. The results (Table 3) show that the adjusted value of coefficient R2 is 0.633 ; this means that the independent variables included in the regression model explain $63.5 \%$ ( $>50 \%$ is good) showing the change of the successful dependent variable of the Lean model. This is a rather high rate, showing that the survey and analysis results are quite suitable for studying the impact of 6 independent factors on the success of Lean.

TABle 3. Results of MUltiple linEAR REGRESSION ANALYSIS

\begin{tabular}{|c|c|c|c|c|c|}
\hline $\begin{array}{l}\text { Correcte } \\
\mathrm{d} \text { R2 }=c\end{array}$ & $\begin{array}{l}\text { Normalization } \\
\text { coefficient }\end{array}$ & & \multirow{2}{*}{$\begin{array}{l}\text { Sig signifi- } \\
\text { cance level }\end{array}$} & \multicolumn{2}{|c|}{$\begin{array}{l}\text { Multicollinear } \\
\text { Statistics }\end{array}$} \\
\hline $51.1 \%$ & Beta & & & Tolerance & VIF \\
\hline Constant & & 0.863 & 0.389 & & \\
\hline LD & 0.424 & 11.686 & 0.142 & 0.860 & 1,026 \\
\hline $\mathrm{NL}$ & 0.359 & 9.947 & 0.000 & 0.858 & 1,020 \\
\hline LQ & 0.271 & 7.522 & 0.000 & 0.860 & 1.013 \\
\hline $\mathrm{NT}$ & 0.270 & 7.503 & 0.000 & 0.735 & 1.011 \\
\hline $\mathrm{CC}$ & 0.258 & 7.126 & 0.000 & 0.816 & 1,02 \\
\hline$\overline{\mathrm{CN}}$ & 0.257 & 3.848 & 0.000 & 0.738 & 1.356 \\
\hline
\end{tabular}

Source: the author's survey data processing results.)

The analysis results (Table 4) show that the independent variables included in the model (: LD, NL, LQ, NT, CC, CN) have sig values $\leq 0.05$; the regression coefficients are all greater than zero, so these factors all positively affect the dependent variable TC. However, the firm size variable has the value sig. $=0.142>0.05$, so there is no impact on the working efficiency at 5\% significance level, 95\% confidence level; The variance exaggeration coefficient VIF of the independent variables is in the range $(1.011-1.356)<2$, showing that these independent variables are not closely related, so there is no multicollinearity phenomenon. Based on the size of the normalized regression coefficient Beta and the order of impact level, a standardized multiple linear regression model is built as follows: 


$$
\mathrm{TC}=0.424 \mathrm{LD}+0.359 \mathrm{NL}+0.271 \mathrm{LQ}
$$

$$
+ \text { NT } 0.270+0.258 \mathrm{CC}+0.257 \mathrm{CN}
$$

Thus, the leader's commitment to companionship and management capacity and labor qualifications are the factors that have the greatest influence on the successful application of the Lean model in enterprises.

Testing the difference (Table 5) of qualitative variables on worker's work efficiency (Independent - sample T- test; Anova depth) has determined that there is no difference in the leadership factors committed to accompany. With the project team, the manager commits to participate, standard work, production rhythm, site layout. However, there is a difference in leadership and management, in which leadership has a higher difference than management, due to the particularity of limited liability companies and joint stock companies specializing in the production of industrial goods. As for the layout of the premises, the author studies many businesses of different sizes according to the revenue because when doing Lean, special attention need paid to the layout of the premises.

TABLE 4. Results OF teSTING THE DIFFERENCE IN CHARACTERISTICS OF DEPENDENT FACTORS

\begin{tabular}{|l|l|l|l|}
\hline Stt & Contents & $\begin{array}{l}\text { Levene } \\
\text { Statistic (Sig.) }\end{array}$ & $\begin{array}{l}\text { Anova } \\
\text { Sig.) }\end{array}$ \\
\hline 1 & $\begin{array}{l}\text { Commitment } \\
\text { management }\end{array}$ & 0.205 & 0.006 \\
\hline 2 & Standard work & 0.943 & 0.962 \\
\hline 3 & Production rhythm & 0.795 & 0.268 \\
\hline 4 & Ground layout & 0.367 & 0.846 \\
\hline
\end{tabular}

\section{Discussion}

The research results also show that the characteristics of the business have a positive influence on the results of applying LEAN. The results of this study also help to explain the determinant of successful implementation of Lean in Vietnamese enterprises.

Firstly, Leadership commitment is especially important for the process of implementing a Lean model. In a company, leaders are very determined, expressed in every word. The direction of the leader's activities makes employees feel the commitment of the leader. Specifically, the daily and weekly reports of the improvement team always have the prompt attention and direction of the company's leaders and management team, which has a positive impact on the success of the project. Kaizen project in business.

Secondly, the technology level of enterprises is 2-3 generations behind compared to other countries in the region [15;20], which leads to LEAN techniques not being able to be deployed. Standards are not fully controlled. Disoco Company applies SMED to the chain that needs to start the motorcycle, but because the entire system of drilling and turning machines is past its useful life, Kaizen ideas and control are difficult in the implementation process $[2 ; 8 ; 17 ; 32]$.
Third, the production management and administration capacity of Vietnamese enterprises is still weak, especially SMEs and state-owned enterprises. Poor cognitive and control capacity leads to low commitment. Disoco's production manager said he was always committed to the LEAN project when interviewed but was often absent from meetings and reports. That poor level of commitment to the process led to decisions made after each meeting not being made. As a result, after 6 months of applying the first LEAN project failed [6].

Fourth, the quality of Vietnamese workers is very low with $81 \%$ unskilled workers [15;27]. Low quality of labor leads to poor awareness and awareness. Poor awareness makes training or rewarding and motivating activities do not have much effect on change.

Fifth, Vietnamese people tend to personalize, short-term vision, lack of sharing is teamwork, many workers think that they only need to complete the work they are assigned, and improvement is not the goal. their job, they also don't care about the productivity of the whole company. Meanwhile, awareness of the role of LEAN requires teamwork and information sharing. The cultural differences that lead to any change efforts of enterprises with LEAN face great difficulty when implementing improvements $[11 ; 13 ; 16]$.

And finally, the production network and supply chain system are not stable and complete. The connection and cooperation in production between Vietnamese enterprises is not high at present. Each business often only cares about its own interests and ignores the interests of partners. The instability in the supply chain along with the lack of linkage between partners is a barrier for businesses to implement J.I.T thoroughly. The two factors "supplier participation" and "customer participation" are not guaranteed, leading to 5/6 enterprises participating in the study not being able to apply LEAN successfully. Only TMV has achieved the highest level of success thanks to the support of the system of suppliers and customers. Six business-specific factors positively affect the success of LEAN for businesses.

\section{Conclusion}

The study presents the essence of applying LEAN production method and factors affecting the success of enterprises when applying it in industrial production. In the context that Vietnamese enterprises have limited resources, low technology level, and low production management capacity, it is difficult to implement synchronously on a large scale throughout the enterprise. On that basis, the article studies the factors of business characteristics that have a great influence on the successful application of the Lean model. Accordingly, businesses that want to apply LEAN successfully and sustainably need to have the companionship of business leaders and choose each step when arranging the premises of Lean application to create habits and form awareness.

\section{REFERENCES}

[1] Ab Wahid, R \& Corner, J. (2009), 'Critical success factors and problems in ISO 9000 maintenance', International Journal of Quality \& Reliability Management, 2(2), 1-13.

[2] Achanga, P., Shehab, E., Roy, R. \& Nelder, G. (2006), 'Critical success factors for lean implementation within SMEs', Journal of Manufacturing Technology Management, 17(4), 460-471 . 
[3] Al-Najem, M. (2014), 'Investigating the factors affecting readiness for lean system adoption within Kuwaiti smalland medium-sized manufacturing industries', doctoral dissertation, University of Portsmouth.

[4] Thai An (2015), 'Vietnamese technology is 2-3 generations behind the world', Baodatviet, last accessed June 28, 2016, from http://baodatviet.vn/khoa- study

[5] Aueungkul, A. (2013), 'An investigation of Critical Success Factors and Thai cultural impact', doctoral dissertation, Univerity of Wollongong, Thailand.

[6] Bakås, O., Govaert, T. \& Van Landeghem, H. (2011), 'Challenges and success factors for implementation of lean manufacturing in European SMES', Proceeding of 13th International conference on the Modern Information Technology in the Innovation Processes of the Industrial Enterprise (MITIP 2011), Norway.

[7] Boynton, A. C \& Zmud, R. W. (1984), 'An assessment of critical success factors', Sloan management review,25(4), 17-27.

[8] Coronado, R. B \& Antony, J. (2002), 'Critical success factors for the successful implementation of six sigmaprojects in organisations', The TQM magazine, 14(2), 92-99.

[9] Dennis, P. (2015), Lean Production simplified: A plain-language guide to the world's most powerful production system, CRC Press.

[10] Drew, J., McCallum, B. \& Roggenhofer, S. (2004), Journey to lean: making operational change stick, Palgrave Macmillan.

[11] Easterby-Smith, M., Thorpe, R. \& Jackson, P. R. (2012), Management research, Sage.

[12] Flinchbaugh, J. \& Carlino, A. (2006), Hitchhiker's guide to lean, Society of Manufacturing Engineers.

[13] Dang Thi Huong (2016), 'Training managers in small and mediumsized enterprises: Some proposed evaluations', Science Journal of Vietnam National University, Hanoi, Economics and Business, 23( 1), 31-39.

[14] Nguyen Dat Minh, Nguyen Danh Nguyen, Le Anh Tuan(2017) "Factors affecting the application of lean production methods in enterprises in Vietnam" Journal of Economic and Political Issues world - No. 12/2017.

[15] Nguyen Dat Minh, Nguyen Danh Nguyen (2017) “Applying Lean production methods in enterprises in Vietnam, the way to success" Economic and Development Magazine No. 1.2017.

[16] Kilpatrick, J. \& Osborne, R. (2006), The R (E) evolution of Lean, Business Breakthroughs Inc.

[17] Kumar, M., Antony, J. \& Douglas, A. (2009), 'Does size matter for Six Sigma implementation? Findings from the survey in UK SMEs', The TQM journal, 21(6), 623-635.
[18] Kundu, G. \& Manohar, B. M. (2012), 'Critical success factors for implementing lean practices in it support services', International Journal for Quality research, 6(4), 301-312.

[19] Duong Thi Lieu \& Nguyen Van Ha (2008), 'Integration and Vietnamese business culture', Proceedings of the 3rd International Conference on Vietnamese Studies, Vietnam Academy of Social Sciences and Vietnam National University Hanoi to co-organize, Hanoi, 1-20.

[20] Nguyen Dang Minh, Nguyen Dang Toan, Nguyen Thi Linh Chi \& Tran Thu Hoan (2014), 'Orientation for applying lean management in Vietnamese small and medium enterprises', VNU Science Journal, Economics and Business, 30(1), 63-71.

[21] Ohno, T. (1988), Toyota production system: beyond large-scale production, CRC Press.

[22] Parkhe, A. (1993), 'Messy research, methodological predispositions, and theory development in international joint ventures', Academy of Management review, 18(2), 227-268.

[23] Perry, C. (1998), Processes of a case study methodology for postgraduate research in marketing', European journal of marketing, 32(9/10), 785-802.

[24] Rockart, J. F. (1982), The changing role of the information systems executive: a critical success factor perspective, Massachusetts Institute of Technology Boston.

[25] Rose, A., Deros, BM \& Ab Rahman, MN (2014), 'Critical success factors for implementing lean manufacturing in Malaysian automotive industry', Research Journal of Applied Sciences, Engineeringand Technology, 8(10), 1191-1200 .

[26] Tracey, M., \& Flinchbaugh, J. (2006), 'HR's role in the lean organizational journey', World at Work Journal,15(4), 49-58.

[27] Pham Minh Tuan (2015), 'Research and application of lean management in small and medium-sized manufacturing enterprises of Vietnam', PhD thesis, University of Economics, Vietnam National University, Hanoi.

[28] Vermaak, T. D. (2008), 'Critical success factors for the implementation of lean thinking in South African manufacturing organisations', doctoral dissertation, University of Johannesburg, South Africa.

[29] Wilson, L. (2010), How to Implement Lean Manufacturing, McGraw Hill.

[30] Womack, J. P., Jones, D. T. \& Roos, D. (1990), Machine that changed the world, Simon and Schuster.

[31] Womack, J. P \& Jones, D. T. (2003), Lean thinking: Banish waste and create wealth in your corporation, revised and updated, Harper Business.

[32] Yang, P \& Yuyu, B. (2010), 'The Barriers to SMEs' Implementation of Lean Production and Counter measures-220-225. 